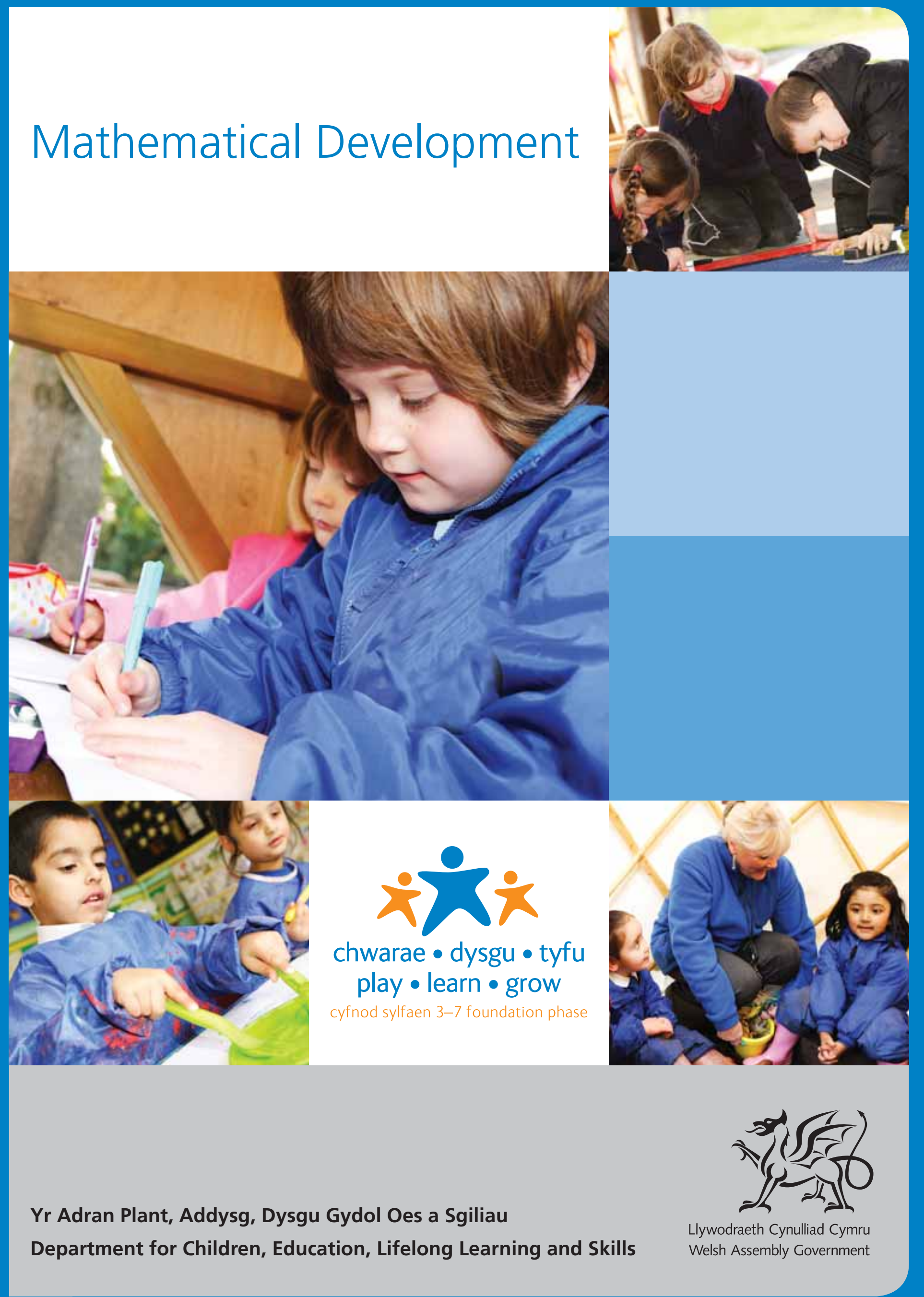




\section{Mathematical Development}

Audience Headteachers, teachers, practitioners, governing bodies of maintained schools and practitioners and management committees in the non-maintained sector in Wales; local education authorities; teacher unions and school representative bodies; church diocesan authorities; national bodies in Wales with an interest in education.

Overview This guidance supports the Mathematical Development Area of Learning in the Foundation Phase Framework for Children's Learning for 3 to 7-year-olds in Wales. The document provides guidance on the skills and knowledge that children acquire, along with case studies on its implementation in settings and schools. The guidance and Area of Learning should not be viewed or delivered in isolation; it should be planned for across the curriculum.

Further

Enquiries about this document should be directed to:

information

Curriculum and Assessment 3-14 Division

Department for Children, Education, Lifelong Learning and Skills

Welsh Assembly Government

Floor 10, Southgate House

Wood Street

Cardiff

CF10 1EW

Tel: 08000836003

Fax: 02920375496

e-mail: C\&A3-14.C\&A3-14@wales.gsi.gov.uk

Additional Can be obtained from:

copies

Tel: 02920375427

Fax: 02920375494

Or by visiting the Welsh Assembly Government's website

www.wales.gov.uk 


\section{Contents}

Background

Introduction

5

Solving mathematical problems

Communicating mathematically

Reasoning mathematically

Case study: The fishing game

Number

Sorting

Matching

Case study: The cows in the field

Counting

Sequencing/pattern making

Case study: Number square work

Case study: Number bonds in the outdoors

Measures and money

Case study: Sunflowers

Mass

Case study: Baking cookies

Length/height

Case study: Shoes

Capacity/volume

Case study: Spheres and chutes

Time

Case study: How many sleeps?

Money

Case study: Cooking activity

Shape, position and movement

Shape

Case study: Coloured shapes

Case study: Straws and matchsticks

Case study: Making a 3-D model 
Position and movement

Case study: The programmable toy

Handling data

Sorting

Classifying

Data handling/graph activities

Case study: Recording our favourite things

Planning/progression

Seven-weekly plan for Mathematical Development

Weekly plan for Mathematical Development

Progress in learning

Number

Measures and money

Shape, position and movement

Handling data

Mathematical Development across the curriculum

Useful information and contacts

Foundation Phase glossary 


\section{Background}

The proposals in the Welsh Assembly Government's document The Learning Country: Foundation Phase 3-7 years included developing a curriculum that linked and strengthened the principles and practice in ACCAC's document Desirable Outcomes for Children's Learning before Compulsory School Age (2000) with the programmes of study and focus statements in the Key Stage 1 national curriculum, to create a rich curriculum under seven Areas of Learning for children in the Foundation Phase. The Foundation Phase curriculum advocates that positive links between the home and the providers of care and education are fostered and promoted.

The Welsh Assembly Government's approach to education and lifelong learning is set in the broader context of our vision for children and young people overall.

We have seven core aims for children and young people developed from the United Nations Convention on the Rights of the Child. These will underpin all of the activities of the Department for Children, Education, Lifelong Learning and Skills (DCELLS).

We aim to ensure that all children and young people:

- have a flying start in life and the best possible basis for their future growth and development

- have access to a comprehensive range of education, training and learning opportunities, including acquisition of essential personal and social skills

- enjoy the best possible physical and mental, social and emotional health, including freedom from abuse, victimisation and exploitation

- have access to play, leisure, sporting and cultural activities

- are listened to, treated with respect, and are able to have their race and cultural identity recognised

- have a safe home and a community that supports physical and emotional wellbeing

- are not disadvantaged by any type of poverty. 
This guidance supports the Mathematical Development Area of Learning in the Foundation Phase Framework for Children's Learning for 3 to 7-year-olds in Wales. The document provides guidance on the skills and knowledge that children acquire, along with case studies on its implementation in settings and schools. The guidance and Area of Learning should not be viewed or delivered in isolation; it should be planned for across the curriculum.

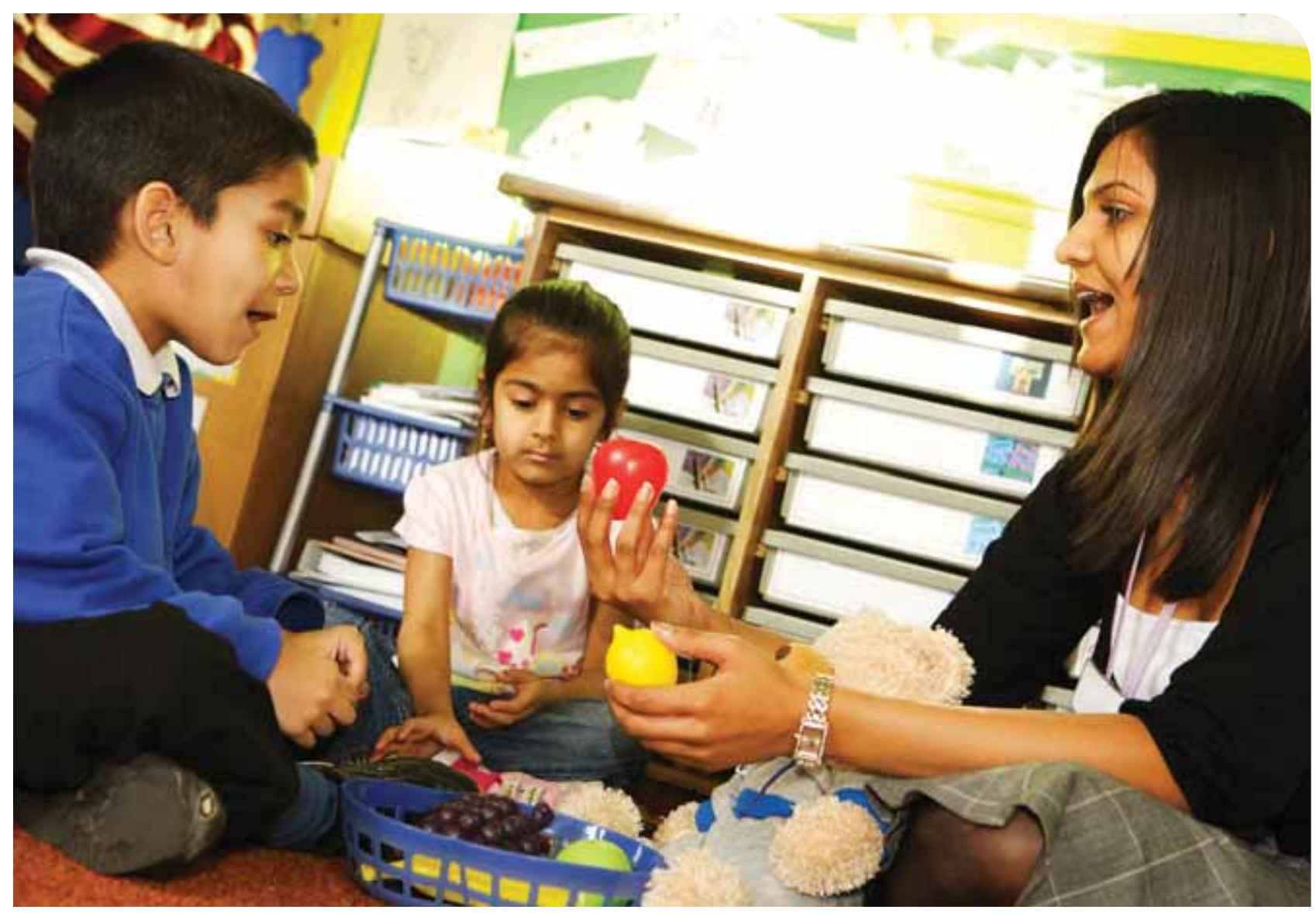




\section{Introduction}

It is important

that

mathematical

activities and

experiences

are planned to

match children's

individual needs.
Children's mathematical development and learning has to be meaningful for it to be effective. Mathematical activities need to be relevant and part of children's everyday lives and experience. Children's cognitive development is linked closely to the development of mathematical skills and concepts, for example problem solving, sequencing and classification.

Children should have plenty of opportunities to investigate and explore their indoor and outdoor environments, to use their energy and curiosity to make sense of their world. It is through these investigations that children develop their understanding of relationships which is vital in understanding mathematics.

Communicating, discussing and talking about mathematics and mathematical concepts is a key and vital part of children's learning and understanding of this area of development. The more active 'hands-on' activities that children experience, the easier it is for them to understand mathematical concepts, such as how things can be ordered and are connected. Experiential learning enables children to identify patterns and relationships and helps them to begin to recognise similarities and differences.

It is important that mathematical activities and experiences are planned to match children's individual needs. They should build on previous achievements to enable children to have continuity in their learning. Opportunities should be provided for children to practise, discuss and consolidate their learning before moving along the continuum. It is crucial that gaps in children's mathematical learning are avoided, so that children do not miss out on essential elements in their understanding of mathematical concepts.

Mathematical Development consists of children's progressive development of concepts, skills, knowledge and understanding in:

- solving mathematical problems

- communicating mathematically

- reasoning mathematically. 
It is through using and applying mathematics that the concepts underlying work on Number, Measures and money, Shape, position and movement, and Handling data will make sense to children in the Foundation Phase.

Through participating in practical and experiential learning activities and experiences, children will:

- make use of their knowledge and understanding of mathematics to solve problems

- communicate mathematical ideas to others orally, pictorially and in writing

- develop mathematical reasoning.

\section{Solving mathematical problems}

Time should be given to allow them to return to the problem several times to see if they can work out the solution.
To solve problems children and adults alike have to draw on their experiences of the world. The younger the child, the less experience they will have to draw on, which is why it is important to give them problems that allow them freedom to investigate without any feeling of failure. Time should be given to allow them to return to the problem several times to see if they can work out the solution. Careful practitioner intervention is essential to ensure that the children do not become frustrated.

The more 'hands-on'/active learning experiences and discussions about their work that the children have, the more their confidence in predicting outcomes of problems will increase. Problem-solving activities should be challenging without being threatening.

Activities that encourage children to work out solutions for themselves will enable them to become thinkers, and to develop knowledge and understanding of mathematics. Talking through and recounting how they solved a problem will enable children to lay down the memory of the process. 


\section{Communicating mathematically}

Recording mathematics in a variety of ways including ICT enables children to communicate their understanding. Early on in their learning, children should have plenty of opportunity to mark-make before being asked to record formally. Through providing practical mathematical activities and allowing children to communicate their understanding in a variety of ways practitioners give children opportunities to:

- use a variety of media to represent different mathematical information

- talk and discuss their work, and communicate through various means/ways

- experience recording mathematics in different ways, including devising their own method of recording

- begin to develop an understanding of what form of presentation is best suited to communicating mathematical information

- develop and present their work clearly

- ask questions and use mathematical language to discuss their work.

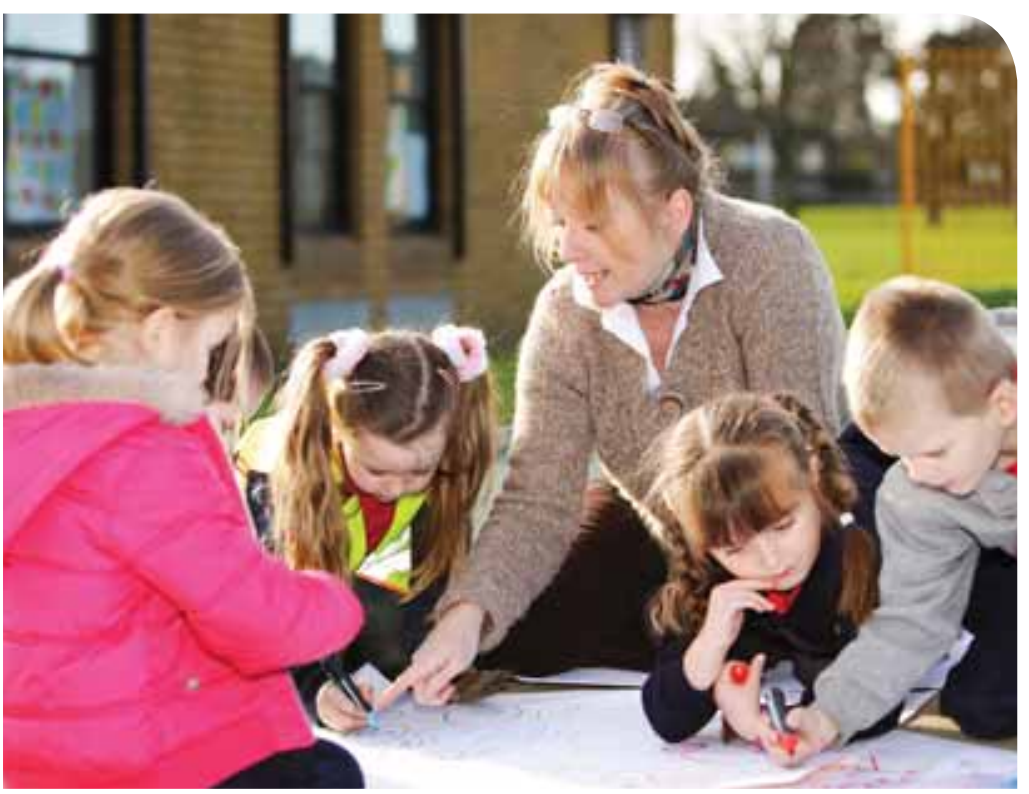

\section{Reasoning mathematically}

Children will begin to predict and use their experience and understanding to reason mathematically/apply logic. Across the Mathematical Development Area of Learning, children should have opportunities to apply logical thinking when, for example, they are undertaking sorting, matching, sequencing or ordering activities. The more experience that the children have, the more sophisticated they can become in recognising relationships and concepts, and in the use of mathematical questioning. 
In this case study, which is entirely child led, a group of children make a pond and some fish and then develop a sophisticated game. In addition to using appropriate equipment and materials to solve a mathematical problem, the children also communicate mathematically and reason mathematically.

\section{The fishing game}

At the start of the activity Alex and Josef were playing with the insulating blocks which are usually used to build wall/tower structures. On this occasion Alex chose to make a large circle shape with the blocks. When Josef asked what he was making Alex replied "a fish pond".

Alex and Josef decided they would make fish to put in their pond, and went to make their own - drawing, patterning and cutting them out. Within a few minutes Wesley, Lloyd, Francesca and Izzy had joined in the activity and were also making fish for the pond. When they had finished making their fish Francesca found some blue material to place inside the fishpond. Lloyd started counting the fish as they were placed inside it.

Wesley then remembered a 'fishing game' that he had previously played at home. He explained to the others how to play the game. They would take turns to catch a fish using a rod. If a child caught a fish, the fish would be retained. If a child did not catch a fish the rod would be passed to the next player to try. Francesca wanted to know how long they would have to try to catch a fish. Josef suggested that they could all count to ten and that it would then be the next person's turn, but the children thought that counting to ten would not be long enough. They all thought for a while and then Alex said "I know, we can use the small egg timer". Everyone thought this was a good idea and Alex went to get the egg timer out of the cupboard.

The children then had a discussion about how they could make their own fishing game. During the discussion, Izzy recalled the fun they had had working with magnets a few weeks earlier. They excitedly collected some paper clips and attached one paper clip to each fish to use in their fishing game. Soon all the children were having fun 'catching' the fish.

Josef asked Wesley "How do you know who is the winner?" Wesley thought carefully about this and then remembered that when he had played the game at home the fish had numbers on them. The children decided that they would put numbers on their fish. 
When all the children were happy with their redesigned fish they resumed playing the fishing game.
When all the children were happy with their redesigned fish they resumed playing the fishing game. They took turns at trying to 'catch' a fish. Each child kept the fish they had caught and when there were no fish left in the pond they excitedly counted the numbers on their respective catches. To do this, the children carefully counted out counters to represent the number on each fish. The more times they played the game the more able the children became at predicting (reasoning mathematically), part way through a game, who would win.

This activity involved number recognition, counting, addition and subtraction and also encouraged mathematical development in the use of cardinal numbers and ordinal numbers.

Over the next few days the children returned to the game sometimes with 'new' players. On these occasions, the experienced players carefully explained the rules to the new players. After each game the pond, the rod and the fish were carefully packed away. The game continues to be popular and is frequently played by the children.

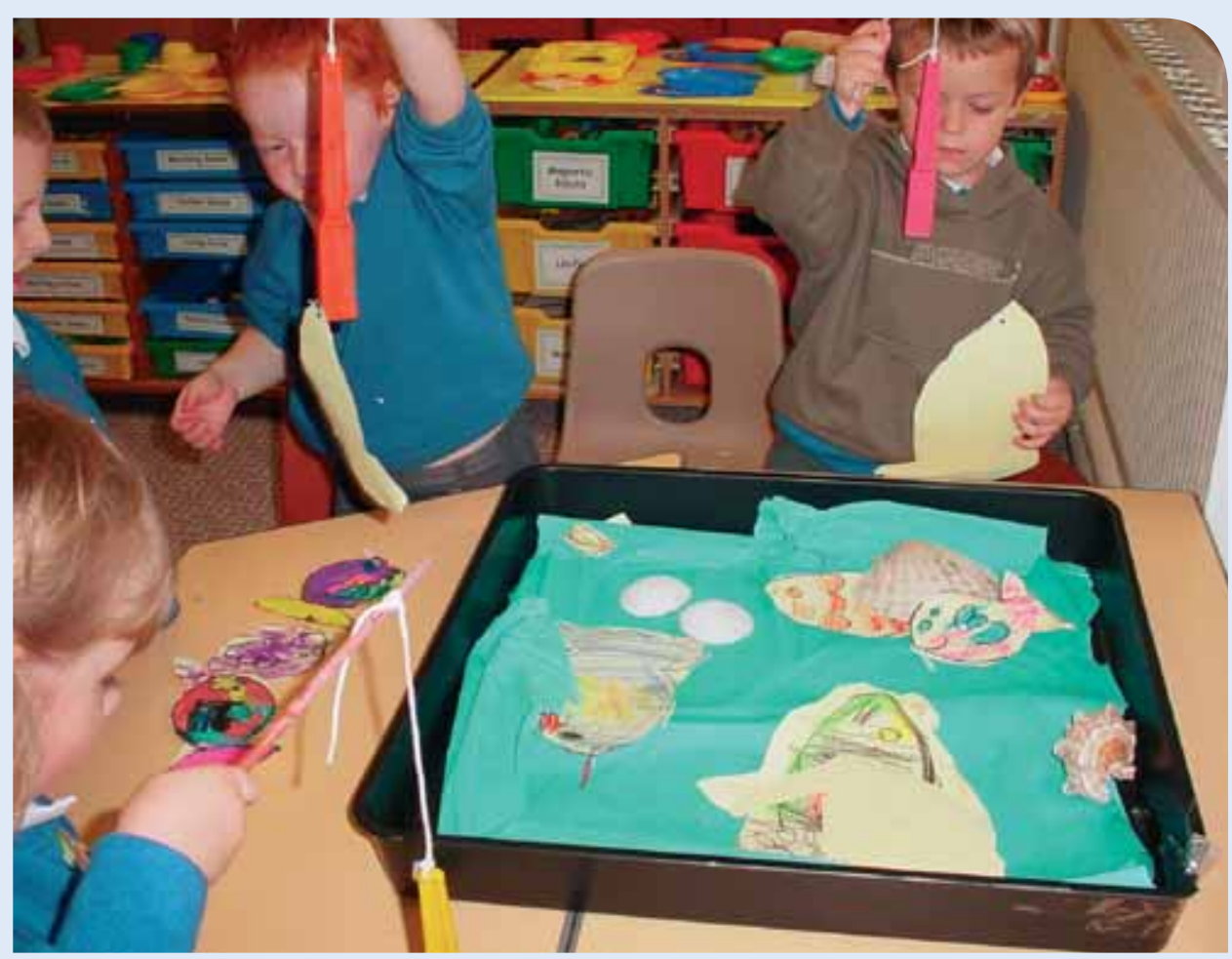




\section{Number}

Through practical experiential learning opportunities using a range of resources (including ICT), children should gain confidence and understanding of mathematics.
One of the most important mathematical concepts for children to acquire is number as it is an important feature of the Mathematical Development Area of Learning and in mathematics generally.

Everyday routines and experiences involve the concept of number, such as sorting, matching, counting and one-to-one correspondence. As the children move along the learning continuum they should begin to:

- recognise and devise patterns

- recognise the relationship between numbers and number symbols

- begin to use specific vocabulary

- understand ordination and place value.

Through practical experiential learning opportunities using a range of resources (including ICT), children should gain confidence and understanding of mathematics. Some of the activities to support the development of number skills could include the following.

\section{Sorting}

Initially children will sort objects in their free play and through structured activities using one criterion to sort. Further along the learning continuum children will be introduced to tallying and graphs to 'sort' such as Carroll and Venn diagrams.

\section{Matching}

Initially children will match objects in one-to-one correspondence activities such as cups with saucers in the home corner. Further along the learning continuum and using their knowledge of addition and subtraction children will be able to match 'sums' to a given number, for example:

Which of the following sums will give you an answer of 20?

$$
10+10=\quad 17+4=\quad 25-5=
$$




A small group
of nursery and
reception children
were playing with
some toy farm
animals on a mat
representing a
farm layout.

A small group

reception children

were playing with

some toy farm

animals on a mat

representing a

farm layout.

\section{The cows in the field}

In their game, the children were trying to put the correct amount of animals in each field on the mat, according to the number displayed in the field.

When I asked them to put three cows in a ploughed field Sam replied: "There isn't any food for the cows in the ploughed field, they should be in a green field. But it would be all right to put pigs in the ploughed field because they like mud." All the children involved could understand the reasoning and began moving other animals around into more suitable places, but still took into account the number in the field.

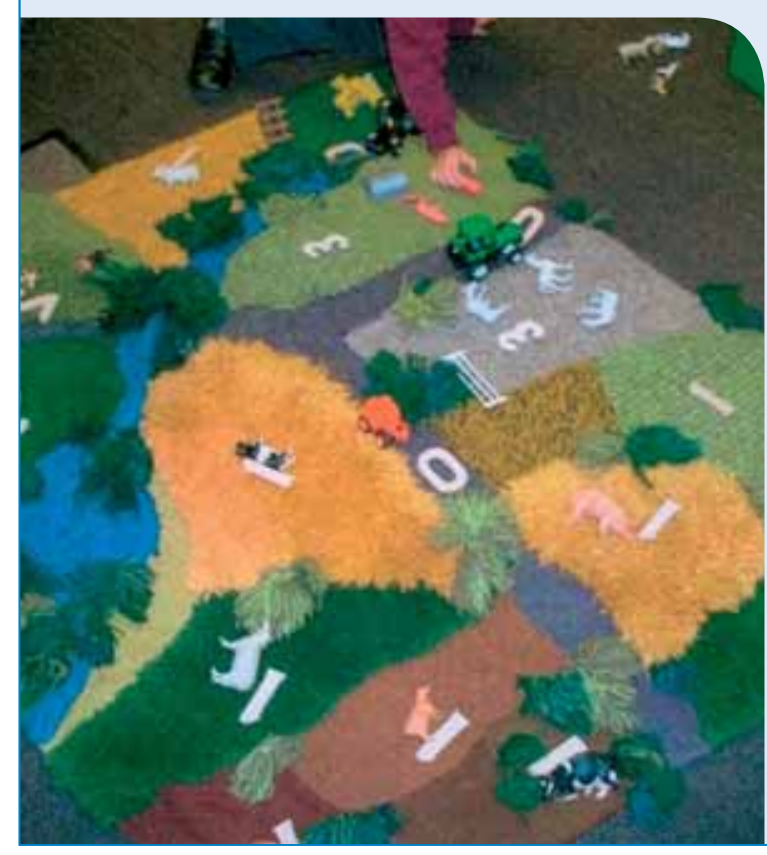

In this activity the children were able to develop and extend appropriate vocabulary relating to position, and their understanding of spatial awareness. In addition, Sam communicated his ideas in his own unique way and the children developed their cooperative skills with their peers.

\section{Counting}

Initially children will count and write numbers 0 to 5, becoming familiar with these numbers through participating in stories, rhymes, etc., that use these numbers. As they move along the learning continuum they will increase their skills and knowledge and will work with numbers up to 100-plus in a variety of activities such as rounding off to the nearest 10 , ordering numbers $0-100$, in addition to participating in multiplication/division activities. 


\section{Sequencing/pattern making}

Initially children will sequence objects to devise a pattern; for example, using shapes in a practical activity they may make a pattern of red $\boldsymbol{\Delta}$ green $\boldsymbol{\square}$ red $\boldsymbol{\Lambda}$, etc. Further along the learning continuum children will devise and record very sophisticated patterns and sequence complex story cards.

In addition to the above, classifying, problem-solving and practical thinking activities will support children's number skills development.

This case study

describes how

identifying

numbers that

were significant to

the children led to

one child making

a prediction.
This case study

describes a

differentiated

outdoor activity

undertaken with

Year 1 and Year 2 children.

\section{Number square work}

Children were introduced to the 100 square and we did lots of activities to reinforce the relationships between numbers, relative size of numbers, etc., I was using our ages as an illustration and pointed out ' 5 ' and ' 6 ' as the children's ages, '50' as my age, and ' 86 ' as my father's age.

The children were really interested in this and we had to go over it several times - then one child said (when I pointed to the ' 86 ' for my Dad) "Gosh (or words to that effect) he's only got ' 1 ' more line to go!" Poor Dad!

\section{Number bonds in the outdoors}

Ladybirds had been drawn onto the playground with chalk. These ladybirds only had a certain number of spots. The more able children had to count the spots and chalk on the extra spots needed to make the ladybirds have 20 spots altogether. Other children had number bonds to ten, and some of the children who were still familiarising themselves with numbers to ten had to match the ladybird to a number card.

This Mathematical Development activity was supported and continued with activities indoors too. Using the ladybirds outside involved/complemented our topic on minibeasts and made learning our number bonds a bit more fun. The children were also active in the outdoors for most of the lesson/activity. 


\section{Measures and money}

Through experiential activities children will gain skills, knowledge and understanding of 'measures', which include the mathematical concepts of:

- mass

- length/height

- capacity/volume

- time

- (value of) money.

By exploring the indoor and outdoor environments, children gain first-hand experiences of recognising, comparing, contrasting, ordering, sequencing, matching different objects and materials.

Differentiated practical activities should allow children to make progress in measuring, initially through using non-standard units, progressing to using standard units confidently and independently. Appropriate open-ended practitioner questioning and discussions with the children will enable them to extend their skills, understanding and mathematical vocabulary.

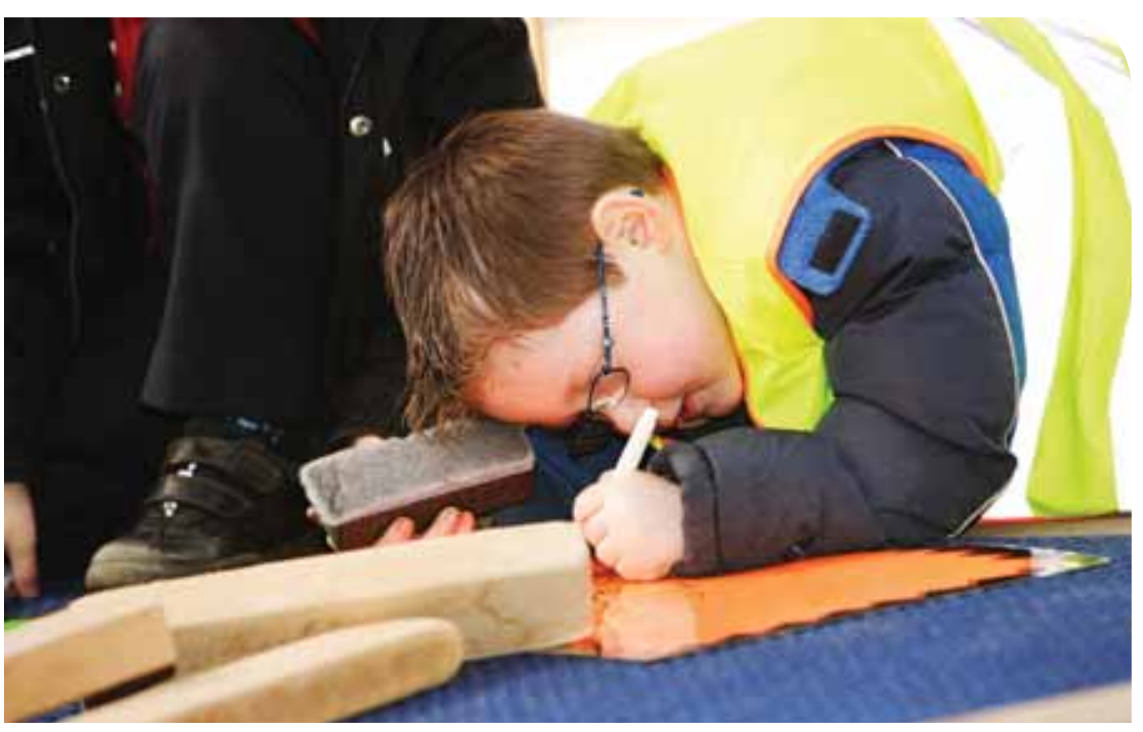

Prior to completing/undertaking a measuring activity, children should be encouraged to develop the skills of predicting and estimating. Through having plenty of opportunities to develop these skills (by discussing and talking through their ideas), children will become more confident and accurate in their answers/responses. Children should also be given opportunities to develop awareness of the use and value of money, initially through role play involving recognition, sorting and use of coins. 


\section{Sunflowers}

Above the stone wall in our outdoor area is a high chain fence that the children wanted to screen by planting tall plants (such as sunflowers) and climbing plants (such as honeysuckle). They planted them from seed and were very involved in their nurture. The children used their mathematical development skills in the garden by measuring the sunflowers regularly, using standard and non-standard measurements, and recording their results on a growth chart.

\section{Mass}

As they handle different objects of varying sizes and weight, children should be encouraged to use the appropriate vocabulary such as heavy/light.
Initially children should develop their skills, knowledge and understanding of weight and mass through experiential activities. As they handle different objects of varying sizes and weight, children should be encouraged to use the appropriate vocabulary such as heavy/light. Allowing children to predict whether they think an object would be heavy/light will develop their understanding that small objects are not necessarily light and large objects heavy.

As they handle a range of objects children should be encouraged to compare and order them by weight, initially using their hands as a balance. Vocabulary should be developed through practitioner questioning, such as 'Which is the heavier/lighter?', 'Do they weigh about the same?', 'Which objects are heavier/lighter than...?', 'Which objects weigh more than/less than...?' Introducing objects that are similar in weight that are difficult to balance by hand will prove the need for introducing a balance. 


In this child-led
case study
Kirsten, Ben and
Kayleigh tried
to make cookie
dough. When
their first attempt
was unsuccessful
they made a
decision based on
the mathematical
concept of more
and less (too
much water);
they were able to
solve the problem
(by adding more
flour to make it
thicker) and made
a decision (how
much flour to
put in).

\section{Baking cookies}

Three groups of children, each with practitioner support, took it in turns to assist with the making of the cookie mixture and then went on to roll out and produce their own cookies ready to put in the oven.

After the activity most of the children went off to wash their hands, but three remained at a table and asked if they could make some more cookies. So the children were left to their own devices. This developed into their own cooking activity, with one of them taking on the role of the practitioner.

Kirsten, who is a confident girl, took on the practitioner role. She made the others wash their hands before they were allowed to touch the ingredients. Kirsten continued to 'act out' the practitioner role by explaining what to put in the bowl and to "be careful not to put in too much water because it makes it sloppy."

All three children then proceeded to have great fun mixing with spoons and their hands, but they soon realised that the mixture was too runny. They thought this was because they had used too much water. After a group discussion they decided to add more flour to make the mixture thicker. Soon their dough was "just right" and they began rolling and moulding the dough.

They involved the rest of the class by inviting them to their café where they had set out plates, spoons, cups and cutlery. Kirsten was the waitress who, armed with a piece of paper and pen, went about taking orders. Ben carefully spooned out the mixture they had made onto plates and into cups. Kayleigh operated the till. 


\section{Length/height}

As children

become

confident in

using non-

standard

units, they

should become

increasingly

aware of the

limitations of

using this type of unit to measure.
To support children's understanding of measuring length, practitioners will need to plan practical, first-hand experiences in everyday

situations, indoors and outdoors, so that children can build up their understanding. Initially, children will need plenty of opportunities to build up and use relevant vocabulary, such as smaller than/larger than, shorter than/longer than, narrower than/wider than, shorter than/ taller than and nearest to/furthest from.

A wide range of experiences should provide children with opportunities to make comparisons where children can discuss their ideas and make predictions on how long, etc., an object is. Moving along the learning continuum, children should begin to measure length using non-standard units such as different parts of the body (hand-spans, feet, strides) and objects like books, string, straws and blocks.

As children become confident in using non-standard units, they should become increasingly aware of the limitations of using this type of unit to measure. At this point standard units should be introduced, such as metres and litres. Further along the learning continuum for those developmentally ready, sub-units could be introduced, such as half-/quarter-litres, and centimetres/millimetres.

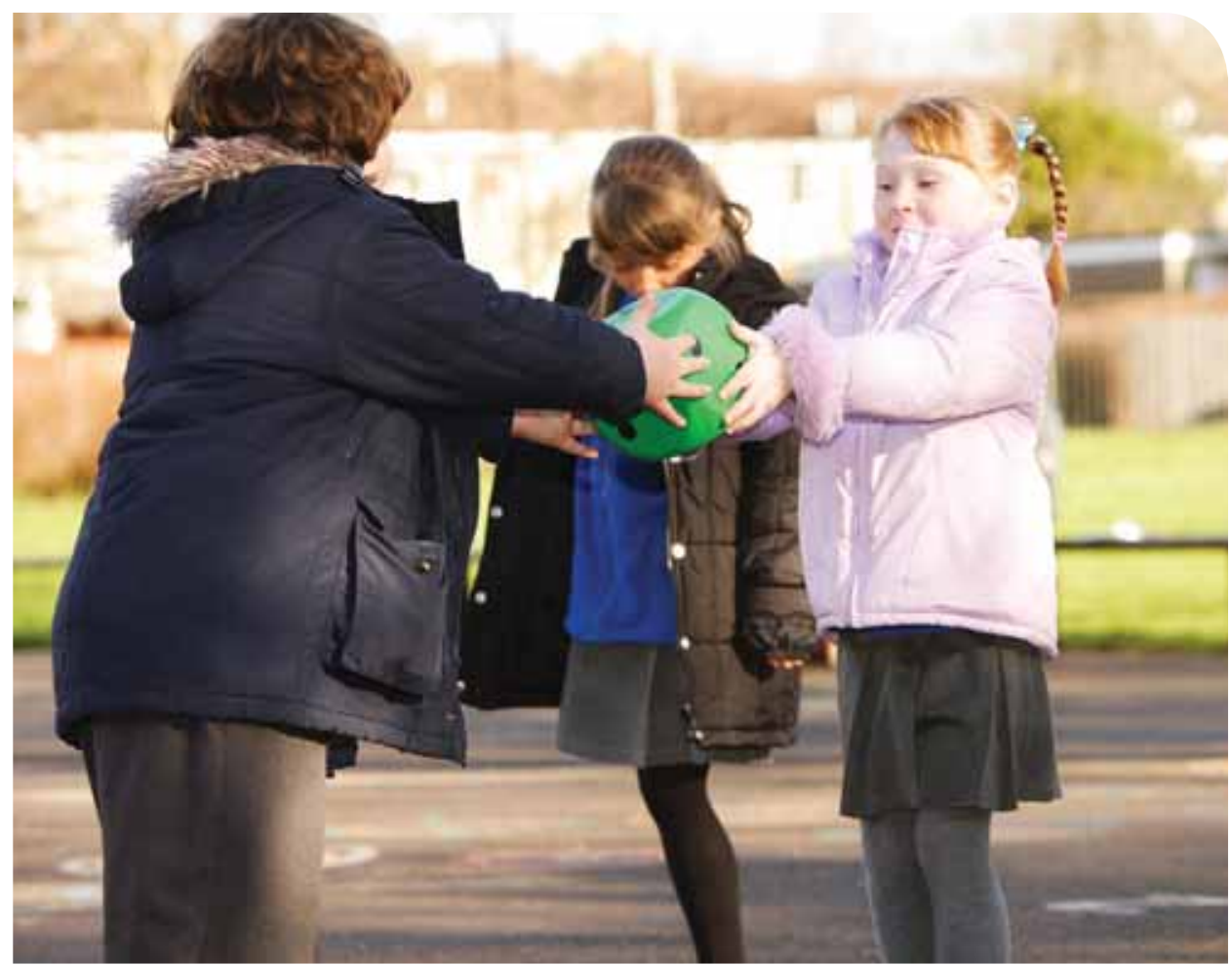




\section{Shoes}

'Shoes' were not a planned topic, but lots of activities developed around this due to the children's interest. 'Who has the biggest shoes?' was a burning question for several weeks in the class and developed from some planned measuring activities. The children were continuously comparing shoe sizes and the numbering system caused great consternation. How size 1 was bigger than size 13 was a difficult concept to grasp. The explanation that seemed to satisfy most children involved a 'baby $\rightarrow$ child $\rightarrow$ adult' time-line with accompanying shoe sizes.

We did rubbings of the soles of the children's shoes and discovered some very interesting patterns. When questioned most of the children seemed to think these were to make you run faster.

We also made and decorated simple mule-type sandals which again provided excellent measuring and comparing opportunities. The children loved wearing them around the classroom.

Around this time we also managed to buy several pairs of wellies. Finding an appropriate size for themselves proved to be a real problem-solving activity for the children! How to pairup the wellies, how to keep them together in the basket and how to mark the size on them were also real problem-solving activities that the children enjoyed. Some interesting questions were raised, such as, "will the sticky tape lose its sticky if you keep taking it off and on?" and "will the chalk numbers come off when you wear the wellies?"

We also painted the soles of the wellies and made footprints by walking along a big roll of paper - again, comparison of size was of interest, as well as the way the footprints 'ran out'. 


\section{Capacity/volume}

Children will experience working with a range of different units through activities such as cooking, building models, experimenting with natural materials and measuring.
Initially, children will develop their skills, knowledge and understanding of volume and capacity through playing with containers and bottles of different sizes and shapes, indoors and outdoors. To support their development children should be provided with a range of wet and dry materials for filling, pouring, etc., such as sand, water, dough, beads and natural materials such as conkers and cones.

Children should be introduced and encouraged to use the appropriate vocabulary (such as full/empty, overflowing, same amount, half full/ half empty, fits, holds more than/holds less than) while working with the different materials.

Through having plenty of opportunities to compare and order containers by filling and emptying them with both wet and dry materials, children should develop their knowledge of volume and capacity. Estimation and discussion of activities related to capacity and volume should be encouraged, along with practitioners asking open-ended questions. Children will experience working with a range of different units through activities such as cooking, building models, experimenting with natural materials and measuring.

Children may initially record pictorially or by making marks to represent their findings. Through discussing the outcomes of using non-standard units, children should eventually begin to recognise the need for standard units. At this point children should be given plenty of opportunities to become familiar with a standard unit such as a litre. This can be achieved by recording in simple tables whether containers contain less than or more than a litre.

As the children move along the learning continuum they will begin to develop their skills, knowledge and understanding of sub-units such as half- and quarter-litres, using containers of those sizes in practical experiential activities. Children's recording skills will become more sophisticated and detailed, linking their skills and knowledge from other mathematical concepts such as number and fractions. 


\section{Spheres and chutes}

Children playing outside were provided with a selection of spheres, balls, beads, conkers, pine cones, a piece of guttering and a piece of waste pipe. It was suggested that they experiment with the materials to see which ones could be sent down the guttering and then through the pipe, onto a tray that would catch them.

Primarily we wanted the children to discover more about the properties of different shapes and perhaps make judgements about which shapes would fit in the guttering and the pipe.

Luke returned to this activity several times over the next few days, clearly enjoying himself.

On one occasion, Luke observed a group of children who were deciding which of the objects they had collected would fit through the guttering. As the children continued their discussions Luke moved over to a nearby tray of gravel and small stones, selected some smooth small pebbles and returned to put them down the waste pipe.

Luke had clearly understood something about the size and shape of the objects that would fit in the waste pipe. 


\section{Time}

Children gain knowledge and understanding of the passage of time initially through daily routines or activities, such as before snack, after lunch, etc.
Activities to support children's understanding of the concept of time have to begin with those that are relevant to their lives. It is the here and now that is important to young children and although they may be able to recall significant events in the past and discuss future events, these are usually to do with some form of celebration or special occasion.

Children gain knowledge and understanding of the passage of time initially through daily routines or activities, such as before snack, after lunch, etc. Often they will refer to long and short time and use vocabulary such as how many sleeps. Children further along the learning continuum will be able to begin to tell the time using an analogue clock and later a digital clock, and will be able to gather simple information from timetables. A wall clock is a useful resource when discussing time with children.

Language development and use of appropriate mathematical vocabulary is crucial to children's understanding of the concept of time. Children need practitioners to talk to them about time, introducing new vocabulary and discussing with them the different concepts of time, such as 'time events' that involve everyday experiences, weekly events, awareness of the seasons and months of the year. Practitioners should also introduce activities that involve 'telling the time' as well as activities concerned with sequencing events in time.

\section{How many sleeps?}

On 1 March all the children were excited about taking part in the St David's Day Eisteddfod, but Jay was especially excited as he knows that his birthday is in March.

After the Eisteddfod Jay asked me "How many sleeps are there to my birthday?" We checked in our 'It's My Birthday Book' and found out that Jay's birthday is on 25 March. Jay then decided that he would make a calendar and he asked how many days were in March. Jay made his own 'calendar' and circled the 25 as this was his birthday.

Every morning before his birthday Jay would tell me how many more sleeps there were until his birthday. 


\section{To support \\ children's \\ understanding \\ of the value of \\ money a cooking \\ activity was \\ planned. The \\ objective was to \\ use a range of \\ mathematical skills \\ to make products \\ to sell at the end \\ of the day to \\ parents/carers.}

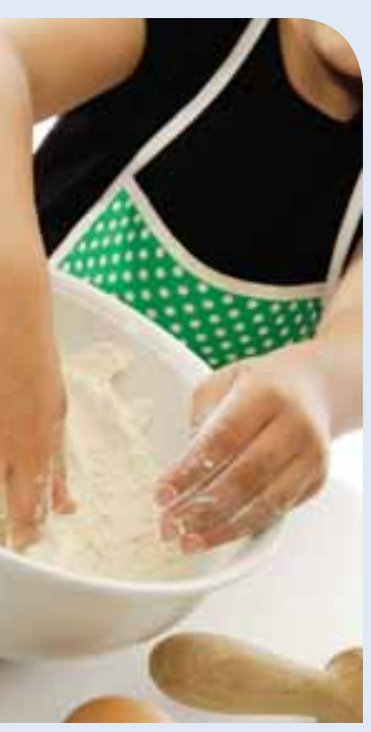

\section{Cooking activity}

This activity was undertaken by a class of Year 1 children. In the initial discussion the children had to come up with 'products' that they wanted to make, cost and sell. The practitioners tried to encourage 'healthy options'. The following are the products that were made:

- dried fruit flapjacks

- containers of fruit salad

- fruit smoothie drinks

- date cupcakes

- fruit ice lollies.

The class was organised into five groups, and working together (with the support of a practitioner) the children measured (weight and volume) the ingredients and followed the cooking instructions. The groups then decided on the price of their products. They discussed the need to cover their costs and what they would like to spend their profits on.

The children set up their 'stalls', labelled the products with the prices and organised themselves ready to sell to their parents/ carers. This activity was a great success; not only had the children gained experience of the value of money, the activity had also reinforced other mathematical skills such as weighing, addition and subtraction. In addition, this activity provided plenty of opportunities for children to socialise with each other. 


\section{Shape, position and movement}

From an early stage of development, children experience different aspects of shape and space.
From an early stage of development, children experience different aspects of shape and space. They handle objects of different sizes and shapes and begin to develop mathematical concepts such as near, far, it fits, in front of, and behind, etc. It is essential for the children's development that they have opportunities to handle objects in 'real situations'/experiences such as through structured role/imaginative play and playing with 'small world' resources.

Shape and space lends itself to working in the outdoor environment, as here the experiences are visual and activities such as maths trails encourage children to explore shape and space. Through the experiential structured activities provided children should begin to recognise and understand pattern, initially through simple repeating patterns, progressing to more complex patterns. As they progress along the learning continuum children should experience a range of activities that introduce and extend their understanding of symmetry.

\section{Shape}

It is important that children develop their knowledge and understanding of 3-D shape alongside their knowledge and understanding of 2-D shape. Before entering the setting/school children will probably have handled 3-D objects, such as building blocks, tins, and boxes and have probably experienced 2-D shapes such as paper for mark-making, flat shapes such as photographs and sticky shapes to make patterns.

Children gain knowledge and understanding of shape through exploration and handling of a wide range of 3-D and 2-D regular and irregular shapes. Through these first-hand experiences children will become familiar with the shape, form and language of these shapes.

Through handling a variety of shapes, children should be encouraged to use the appropriate vocabulary to describe the shapes; for example, flat, solid, straight sides and curved. When handling 3-D shapes, children should discover some of their properties, such as it rolls/does not roll, it is round, pointed and it 'fits together'. Children should make models and be involved in sorting and matching activities. As they become familiar with the shapes, children should begin to recognise and name them. 
As children's hand-eye coordination develops, their pattern making will become more detailed and sophisticated. This will involve investigations of shapes and tessellation. Further along the learning continuum, children will develop their understanding of vocabulary such as faces, edges and corners, and the relationship between 3-D and 2-D shapes.

\section{Coloured shapes}

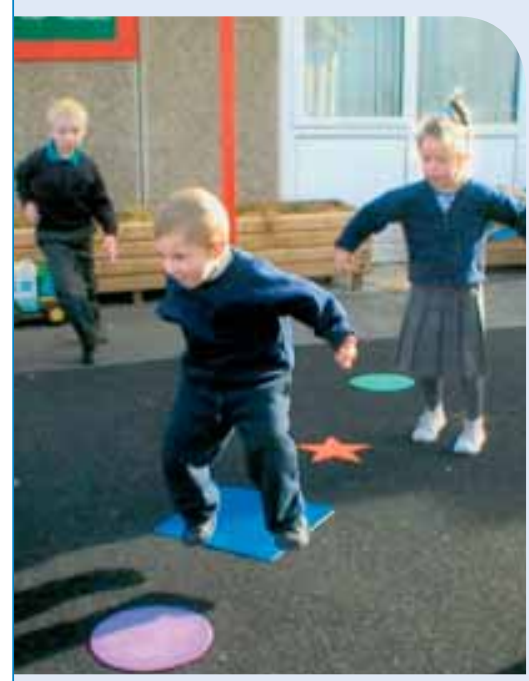

The photograph shows three children developing their selfconfidence, balance and creative play when coloured shapes were moved to the outside area.

The children devised a game, jumping from one shape to another. The fact that they were playing together and not alongside each other was remarkable, plus the fact that nobody realised how high the children could jump.

The game covered so many areas of the curriculum, such as mathematics, personal and social skills, language, communication and physical skills. 


\section{Straws and matchsticks}

After several weeks of work on 2-D shapes we provided straws and matchsticks for the children to construct their own shapes. They made squares and rectangles as well as circles. The children also extended the activity by joining together endless straws and matchsticks to see who could make the longest construction.

We challenged the children to make one as long as the nursery/the carpet area. There was a lot of conversation about 'longest' and 'shortest'. It was also an opportunity to show the importance of starting from the same point when making comparisons.

\section{Making a 3-D model}

The children were set the task of making a 3-D model of an elephant. They were provided with a number of different 3-D shapes - cylinders, cubes, cuboids. They had to name each of the shapes in turn and sort them into sets. Once they had achieved this they were provided with glue, glue sticks and sticky tape and asked to work together to make a 3-D elephant. As a group they had to decide on the shapes used and the materials that they were going to fix them together with.

As a group they worked collaboratively, led at first by a practitioner who encouraged them to think things through and to vote on ideas and suggestions that each group member had. As a direct result of the practitioner's role during the activity each time a decision had to be made the group would take a vote without practitioner intervention. They worked together to decide on the shapes used and the position of the shapes in the model. One group member appeared to lead the other children when it came to the ideas for fixing the boxes together. However, the practitioner quickly responded by asking the other group members for some ideas and included all members during this stage of the activity. The end result was a completed 3-D model of an elephant that the group had worked together to produce. 


\section{Position and movement}

Through physical activities and using small world resources, children can begin to develop their positional vocabulary, such as indoors/ outdoors, over/under, above/below, in front/behind, on top of and underneath. To support the development of this vocabulary, children can be given instructions to follow - for example, 'stand behind the yellow line, jump forwards and put your hand in front of your face'.

Battery-operated resources, as well as programmable toys, are useful for reinforcing directions, etc. These can be used indoors and outdoors and children can take them on a journey. Mark-making and art activities are also beneficial in giving children experiences of left-to-right orientation, of filling space and for the introduction of turns through pattern making. In initial discussions about turning, children should begin to identify what objects around their homes and in the setting/ school turn; for example, clocks, wheels, handles, etc.

As children become more confident in their understanding of (shape, position and movement) space and turns, right angles could be introduced through using their bodies in physical activities and by folding paper so that children can see what a right angle looks like. The children can then find right angles in their learning environments. Moving along the learning continuum, children can be introduced to a turn, half-turn and quarter-turn.

Within the indoor and outdoor environment, space and adequate surfaces should be carefully planned to provide opportunities for:

- individual and small group work

- independent learning

- group sessions with a practitioner

- storing work in progress

- displaying work

- setting out interactive displays. 


\section{This case study illustrates how children were provided with opportunities to extend their Welsh Language Development skills during a Mathematical Development activity.}

\section{The programmable toy}

We wanted to introduce the children to a programmable toy (an early Roamer). It has a simple set of buttons which program the toy to move forwards, backwards and turn right or left. It also has a 'Clear Memory' button to delete all previous instructions, and a 'Go' button.

We had been looking at houses and homes during the term and the children had been provided with a large floor plan of a bungalow. The rooms had been labelled in Welsh and there were doors, walls and corridors. There was also a 'Croeso' mat on which the programmable toy had to start.

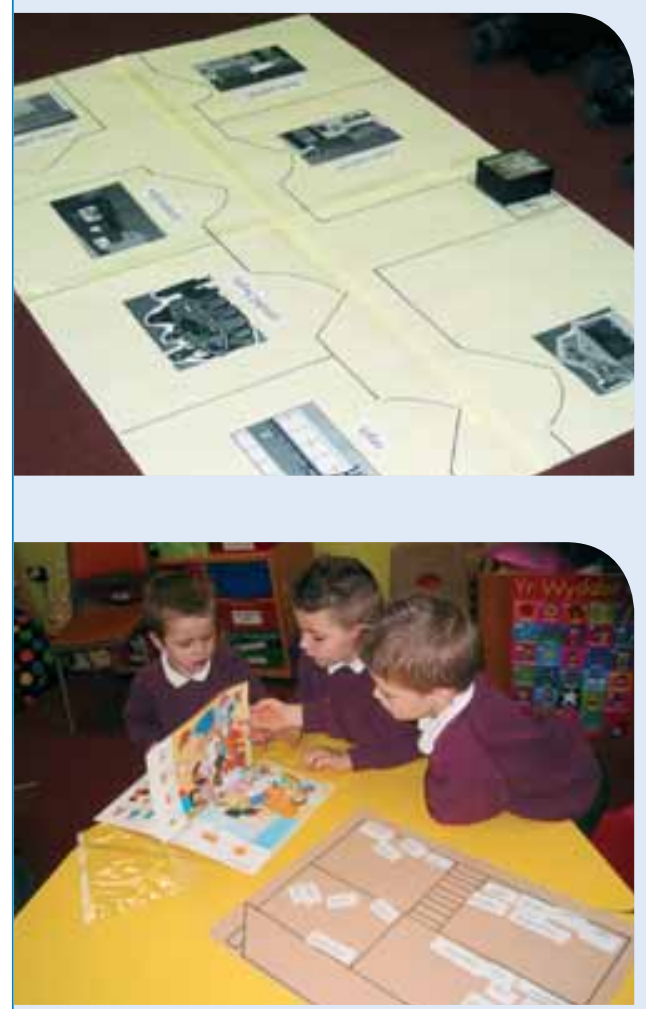

The children were given the opportunity to program the toy to move into any of the rooms. Gradually they learned from one another how many times they needed to press the 'forward' button to reach certain points on the plan.

The children were then encouraged to make their own plans - they decided to work in small groups. They had been given a set of labels, some in English and some in Welsh, which they had to sort and stick in the correct room in the house. They continued to use the Welsh words to label the rooms in their own houses. If they did not understand a word, they were encouraged to look up that word in the Welsh word-bank kept in the classroom.

After they had made their own plans the children wrote instructions for each other so that they could program the toy around their own house. They automatically continued to use the Welsh words on their own plans. 


\section{Handling data}

Children begin to develop their skills in handling data alongside their developing number skills, for example when sorting and matching objects. Everyday routines and activities in the indoor and outdoor environment should provide children with opportunities to collect data:

- for a variety of defined purposes

- from a variety of sources, including ICT.

As they move along the learning continuum, children should:

- handle different forms of data

- begin to represent collected data, initially using real objects or diagrams

- progress to using a variety of simple charts, graphs, diagrams, tables or databases

- begin to compare, record and interpret data and present their findings.

Some of the activities to support the development of handling data skills could include the following.

\section{Sorting}

Initially children will sort objects or pictures by comparing their similarities, moving on to an awareness of contrasting qualities. As they progress children will become aware of when objects are different and do not belong in the same category. They will also begin to sort and classify objects using more than one criteria.

\section{Classifying}

Initially children will classify groups of objects or pictures using one criterion. As they progress children will begin to classify collections of objects using more than one criterion related to their properties.

\section{Data handling/graph activities}

Initially children will collect and organise information in simple ways. As they progress children will begin to interpret data and extract information from an increasing range of charts, diagrams and tables. 


This case study
illustrates how
young children
were introduced
to the concept of
simple graphical
illustration and
then went on to
include one of
the steps in the
process in their
own activities.

\section{Recording our favourite things}

The work on weather was largely initiated and developed by the children themselves, with some guidance where necessary.

We have a daily date/season/weather chart and after several rainy days some children were disappointed that it was another rainy day. This prompted a discussion on weather preferences. I then asked "how many like ... weather, etc." Some of the children were finding it difficult to count on the carpet, but Abbie came up with a solution: "Let's go into different groups." The children organised themselves into sunny/rainy/stormy, etc., groups and then we counted more successfully.

I started a simple graphical illustration of what we had done on the white board. The children all contributed their faces to show their preference. We also talked about why we liked certain types of weather, which produced another lively discussion.

The 'weather' groups then went on to do weather pictures and contributed to an appropriate collage, which I then framed into a 'window' and displayed.

We also converted a corner in the room into a weather corner sunny with buckets and spades, sun hats, sunglasses, etc., rainy with umbrellas, wellies, puddles, etc. - and this encouraged some lovely imaginative play.

The children have gone on to use the idea of moving into groups in order to count themselves in other areas, such as sandwiches/school dinners/home at lunchtime, choices of which story to read or which music to listen to, etc. The beginnings of a democratic system, perhaps. 


\section{Planning/progression}

As children will move along the learning continuum at different rates it is important to observe children's skills, consider individual needs and take into account the range of mathematical development when planning activities. Relevant learning experiences will enable children to make steady progress appropriate to their stage of development.

Progression in children's mathematical skills can be supported by opportunities for:

- play

- experimentation

- talking/discussing

- predicting/estimating

- practise

- review

- application

- evaluation.

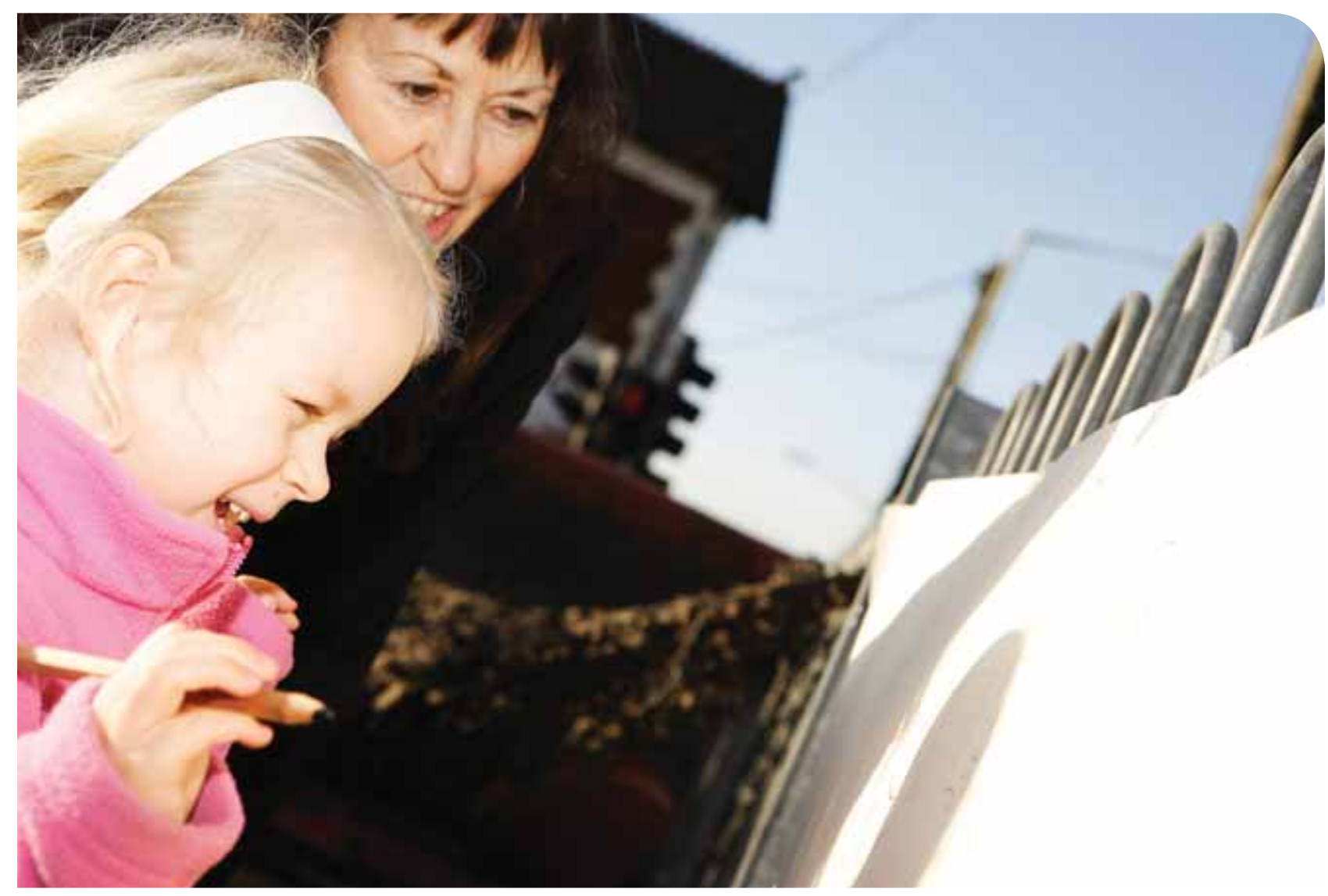




\section{Seven-weekly plan for Mathematical Development}

The following example of planning sets out how one setting plans for the delivery of Mathematical Development over a seven-week period.

\begin{tabular}{|c|c|}
\hline Week & Activity \\
\hline 1 & $\begin{array}{l}\text { Number } \\
\text { Count numbers one to five } \\
\text { Recite number rhymes }\end{array}$ \\
\hline 2 & $\begin{array}{l}\text { Number/pattern } \\
\text { Look at patterns found in the environment } \\
\text { Discuss differences in size, colour and shape }\end{array}$ \\
\hline 3 & $\begin{array}{l}\text { Number/pattern } \\
\text { Sorting items into groups (according to shape, colour, size) } \\
\text { ICT - make patterns using the drawing program }\end{array}$ \\
\hline 4 & $\begin{array}{l}\text { Number/pattern } \\
\text { Count numbers one to ten } \\
\text { Copy repeating patterns (from wrapping paper) }\end{array}$ \\
\hline 5 & $\begin{array}{l}\text { Number } \\
\text { Recognise number one } \\
\text { Draw number ' } 1 \text { ' in sand } \\
\text { Game: Find me } 1 \ldots\end{array}$ \\
\hline 6 & $\begin{array}{l}\text { Number } \\
\text { Recognise number two } \\
\text { Draw number ' } 2 \text { ' } \\
\text { Game: Matching socks game (also using ICT) }\end{array}$ \\
\hline 7 & $\begin{array}{l}\text { Number } \\
\text { Recognise number three } \\
\text { Draw number ' } 3 \text { ' } \\
\text { Game: Musical dot game (count beats to match dots) }\end{array}$ \\
\hline
\end{tabular}




\section{Weekly plan for Mathematical Development}

The following is an example of weekly planning for Mathematical Development.

\section{Week beginning...}

\section{Skill}

\section{Activities}

To be able to count, recognise and order numbers within zero to five.

- Use the class washing line every day. Put the numbers in the correct order.

- Use ordinal numbers when sequencing stories and pictures, e.g. 'What happened first?', 'What happened next?', 'What happened last?', 'Which little pig built a house of bricks?', 'Which house was built first?'

- Arrange chairs to make a bus. Put numbers on the seats. Match the ticket to the numbered seat.

To be able to sequence objects. - Copy and create sequential patterns using blocks.

To be able to sequence pictures

- Use simple sequencing cards and puzzles to tell a story. and events.

To be able to make comparisons and learn appropriate vocabulary.
- Use comparative language when talking about the Three Billy Goats Gruff, e.g. biggest/smallest. 


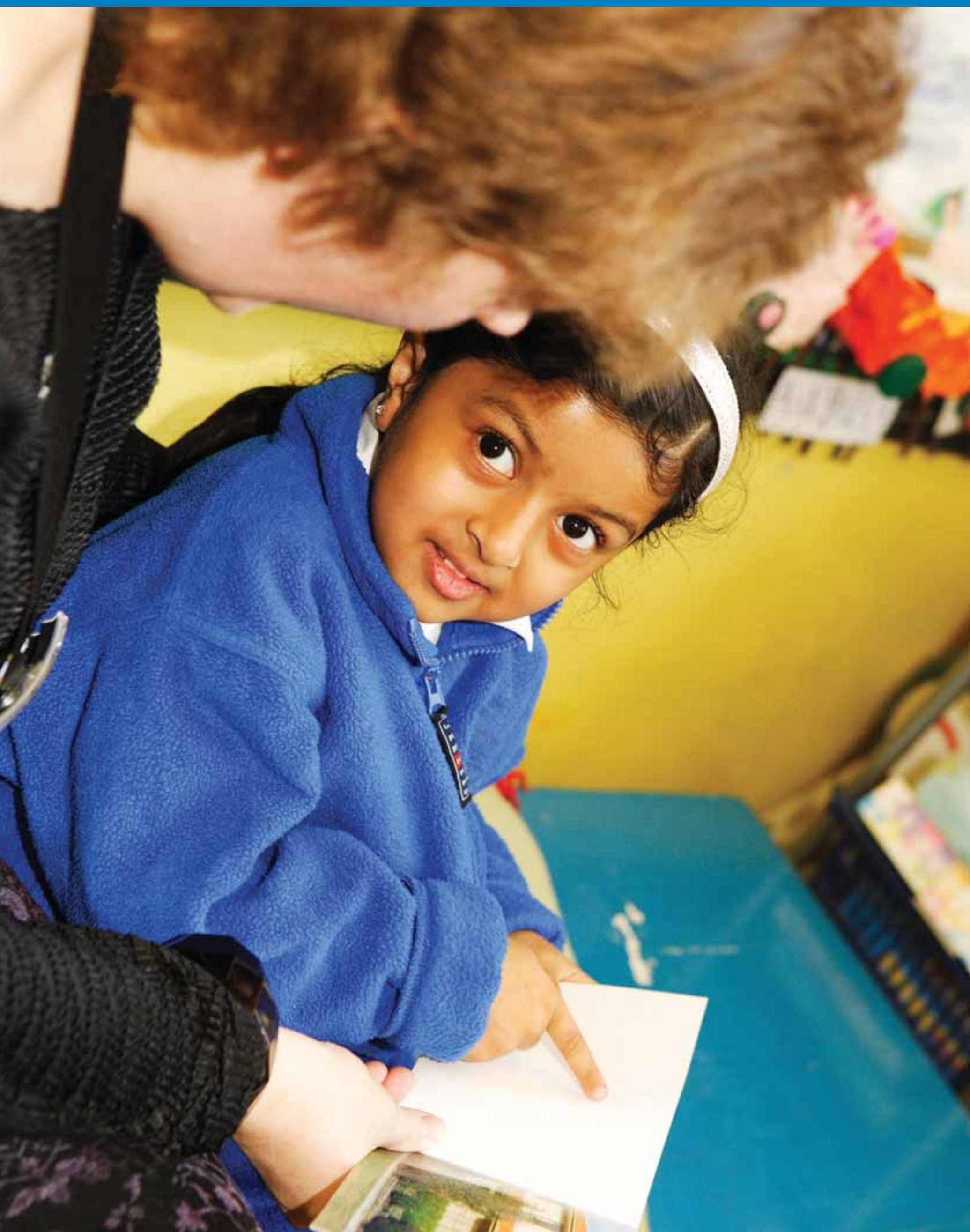

(1)

34 Mathematical Development 26,4 


\section{Progress in learning}

Children will progress through the various elements when they are developmentally ready.
Provision for children's Mathematical Development should be planned as an integrated whole, and take account of relevant activities in other Areas of Learning. Children will progress through the various elements when they are developmentally ready.

Throughout the Foundation Phase, taking part in mathematical activities that require solving mathematical problems, communicating mathematically and reasoning mathematically will enable children to make progress in their ability to:

- use mathematical language and skills in their role play; select and use the appropriate mathematical ideas and methods, equipment and materials to solve practical problems; develop a range of mathematical approaches, and look for ways to overcome difficulties; organise and check their work, and work systematically

- understand mathematical language (number, shape, comparatives) and use it to talk about their work, responding to and asking mathematical questions; explain their methods of reasoning orally and, where appropriate, in writing; represent their work in a clear and organised way, using symbols where appropriate; present their work in a variety of forms including words, pictures, models, charts and number sentences

- sort and match, justify their decisions; make simple estimates and predictions; begin to check answers in different ways; interpret their answers to a particular calculation within the context of the given problem (for example, remainders following division).

\section{Number}

Throughout the Foundation Phase a wide variety of activities will involve children in counting, reading and writing numbers, comparing and ordering numbers, using number patterns and relationships. In addition a variety of methods of calculation, and methods of solving numerical problems, will enable children to develop a sound basis for work in number and to make progress in their ability to:

- say number names accurately in play and use them in familiar contexts; know the number names, and recite them in order from and back to zero; count reliably, initially small sets of objects; count on and back in steps of different sizes, and from different numbers 
- record numbers, initially by making marks, progressing to simple tallying and writing numerals; read and write numbers, initially to 10 then to 100 and beyond; know what each digit in a two-digit number represents, including the use of zero as a placeholder; recognise and use in context simple fractions; use negative numbers in the context of temperature and decimal notation in recording money

- understand and use the vocabulary of comparing numbers, including ordinal numbers; order whole numbers to at least 100 , and position them on a number line and a 100 square; approximate numbers to the nearest 10 or 100

- explore patterns in number tables and sequences; match objects in real contexts, and compare sets by matching objects; understand the commutative property of addition, and the relationship between addition and subtraction; mentally add 10 to any single-digit number, then add or subtract multiples of 10 to or from a two-digit number

- use the vocabulary of addition and subtraction in practical and oral activities; relate addition to combining two groups of objects, and to counting on; relate subtraction to taking away, counting how many are left, and to counting back; use the + and - sign and $=$ to record mental calculations in a number sentence; understand that subtraction is the inverse of addition; use mental recall of the 2 , 3, 4, 5 and 10 multiplication tables in solving problems; know and use halving as the inverse of doubling

- recognise, sort and use coins, find totals and give change; use mental strategies to solve problems using counting, addition, subtraction, doubling and halving; recognise situations to which the operations of addition and subtraction apply, and use them to solve problems with whole numbers, including contexts, that involve money or measures; recognise situations to which multiplication and division apply, and use them to solve problems with whole numbers, money or measures, understanding and dealing appropriately with remainders; choose a suitable method of computation, using apparatus where appropriate, or a calculator where the numbers include several digits. 


\section{Measures and money}

Talking about and taking part in a wide variety of practical activities involving measures (mass, length, capacity and time) will enable children to progress in their ability to:

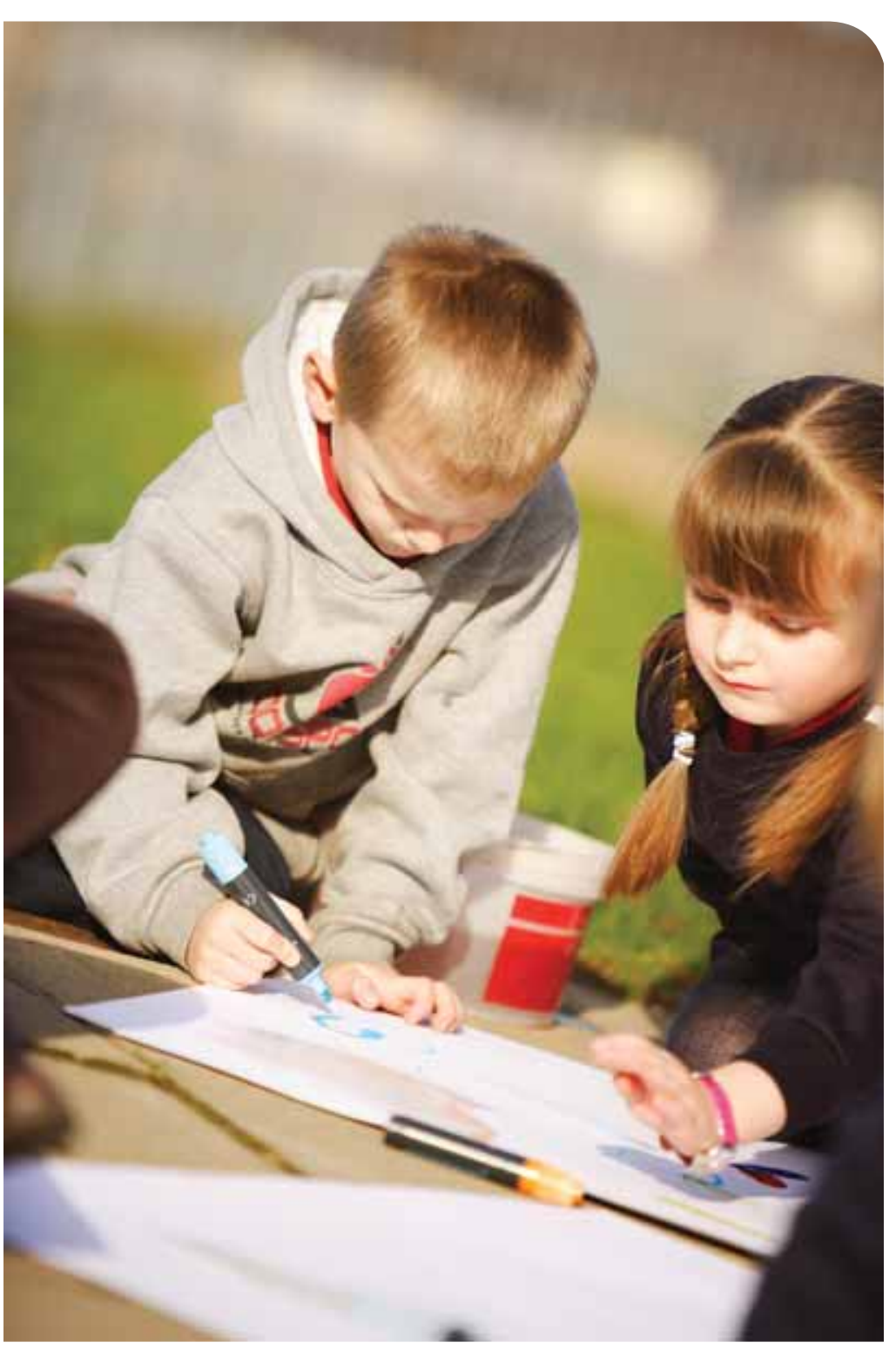

- compare and order two or more objects by direct observation in terms of length, height, weight or (by filling and emptying containers) capacity, using the language of comparison to talk about the ordering; measure using uniform non-standard units, and see the need for standard units; use standard metric units of length, mass and capacity and choose units appropriate to a situation; choose and use appropriate measuring equipment, reading and interpreting numbers and scales with some accuracy

- talk about the time of day in relation to regular activities, know and order days of the week, months and seasons, and sequence two or three familiar events; understand the passage of time in relation to everyday life, and use standard units of time

- recognise, sort and use coins, find totals and give change; recognise situations to which the operations of addition and subtraction apply, and use them to solve problems with whole numbers (including contexts) that involve money or measures. 


\section{Shape, position and movement}

Talking about and taking part in a range of practical activities involving patterns and properties of shape and position, as well as movement in space, will enable children to progress in their ability to:

- use a variety of 3-D and 2-D shapes to make models, pictures, patterns and sequences, working with increasing care and accuracy; talk about the properties of regular and irregular shapes, identify similarities and differences and use everyday language to describe features of familiar 3-D and 2-D shapes referring to properties such as the numbers of flat surfaces, faces, corners, types of side; know the names of solids such as a cube, cone, sphere, pyramid, cylinder and flat shapes such as a circle, triangle, square, rectangle, pentagon, hexagon, octagon; recognise and use the geometrical features of shapes, including vertices, sides, edges, surfaces of 3-D shapes and reflective symmetry in 2-D shapes

- understand and use a range of vocabulary to describe position, direction and movement; develop an awareness of movement through space during physical activities, explore movement using programmable devices, and follow and give directions for simple movements; talk about things that turn, and recognise whole, half- and quarter-turns, to the left or right; know that a right angle is a measure of a quarter-turn, and recognise right angles in squares and rectangles; recognise movements in a straight line (i.e. translations and rotations), and combine them in simple ways.

\section{Handling data}

Talking about and taking part in a range of practical activities involving handling data will enable children to progress in their ability to:

- sort and classify collections of objects using one or more criteria related to their properties, and talk about the classification

- collect and organise information in simple ways

- collect, record and interpret data using an increasing range of charts, diagrams, tables and graphs to communicate findings

- extract information from an increasing range of charts, diagrams or tables and talk about their findings; enter and access information in a simple database. 


\section{Mathematical Development across the curriculum}

Effective provision for developing children's understanding of mathematical concepts needs careful planning across all Areas of Learning to ensure children have opportunities to develop, apply and extend their skills of using and applying mathematics, number, measures, shape and space through a variety of media, including ICT. There are many opportunities for children to develop skills, concepts, knowledge and understanding within the other Areas of Learning and within the different teaching areas in the setting/school. For example children could:

\section{Personal and Social Development, Well-Being and Cultural Diversity}

- use odd/even numbers when taking turns during social routines/ circle time

- create class/group graphs on children's preferred/personal choices, for example, their favourite healthy snack

\section{Language, Literacy and Communication Skills}

- use different forms of communication such as speaking or through art and craft, identifying which vessels hold the most/least and describing the process that they used to find out

- listen to/discuss/read, then retell in mark-making, pictorial or written form stories that have a number theme or focus

\section{Welsh Language Development}

- develop positional vocabulary and number through nursery rhymes, games and songs in Welsh and then use them in practical activities

- look at, discuss and produce their own patterns based on patterns and prints from Wales 


\section{Knowledge and Understanding of the World}

- observe and record numbers, shapes and patterns in the outdoor learning environment

- develop timelines to show the passage of time - initially of events in a day through to a specific time in history

\section{Physical Development}

- use positional, number and comparative mathematical language when moving around in physical activities outdoors and when using programs on the computer

- use timers/stopwatches to record how many jumps/hops/claps children can do in one minute

\section{Creative Development}

- use different types of music, songs, or rhymes to count out and record the patterns and beats in a rhythm

- use a variety of media, including ICT to create 3-D and 2-D shape models and pictures to reflect shape, space and pattern observed in works of art.

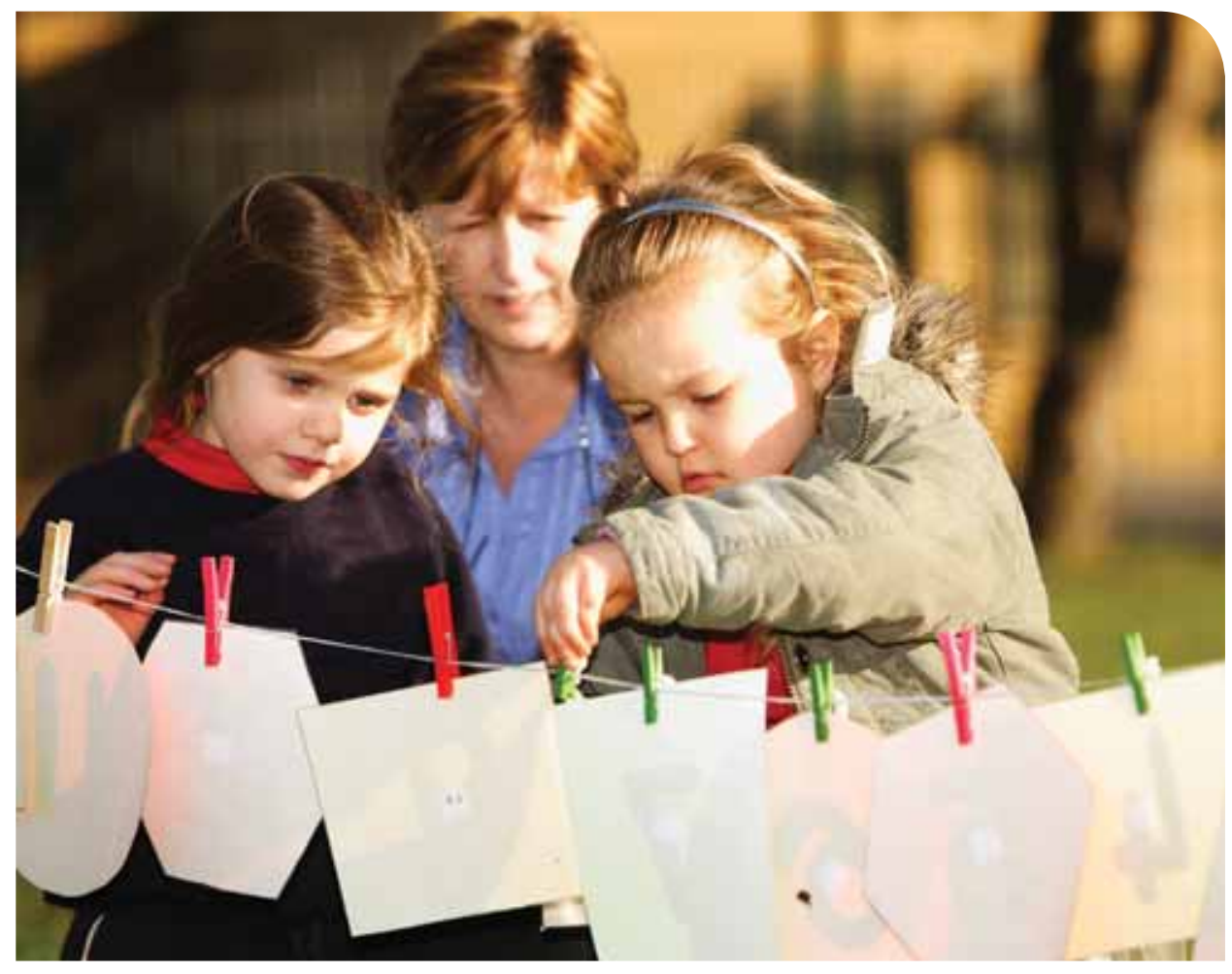




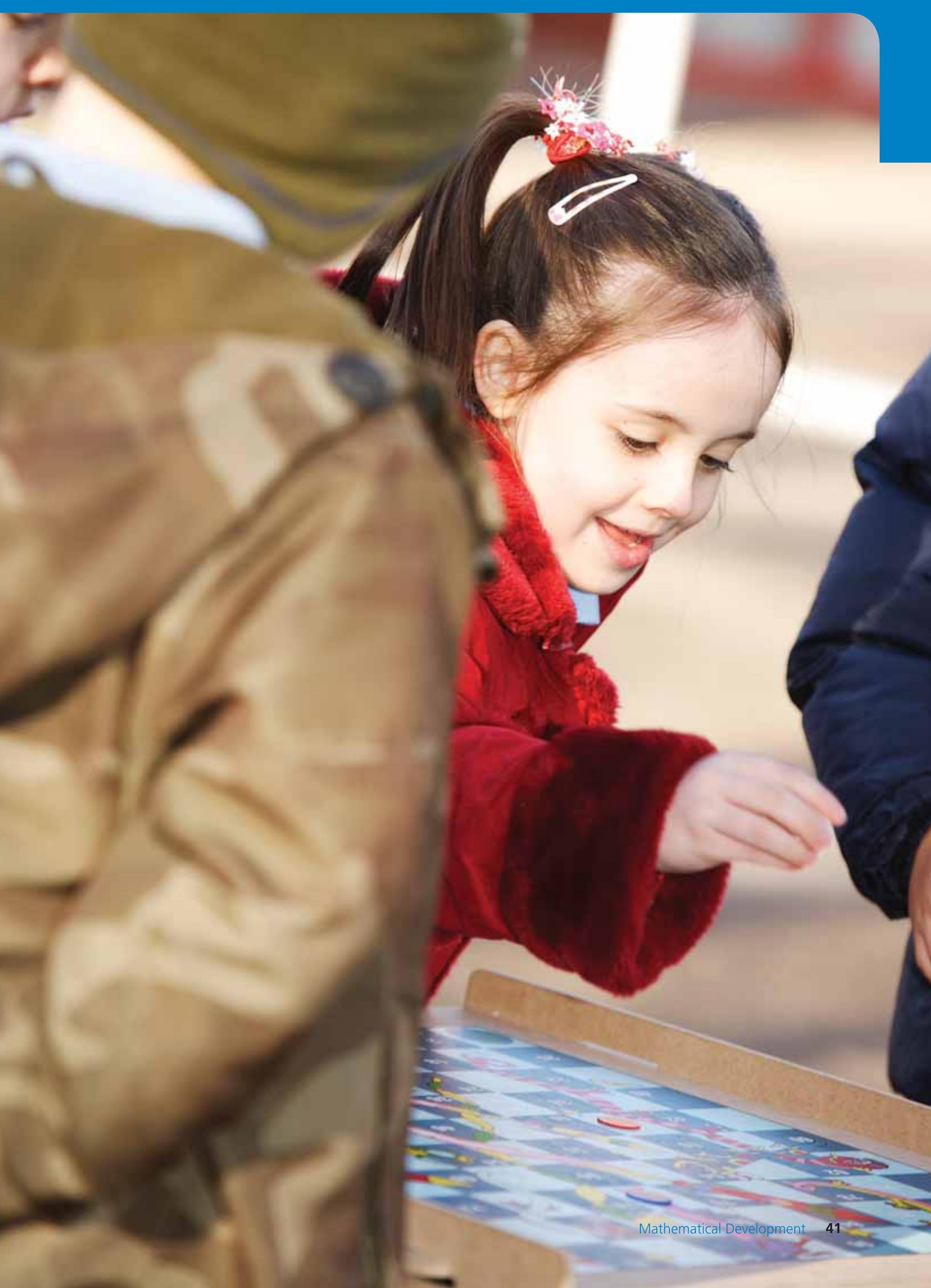




\section{Useful information and contacts}

The Brain Buster Maths Box (years 1 and 2): The NRICH Problem-Solving Kit by J M Murray (BEAM, 2006)

ISBN: 9781903142400

Canu Sy'n Cyfrif by M Kedward (Cyhoeddiadau Curiad, 2007) ISBN: 9781897664995

Cyfres Dros yr Enfys: Cyfrif/Counting by G S Jones (Atebol, 2006) ISBN: 9781905255382

First Steps: Beginning Mental Maths by D C Perkins and E J Perkins (Domino Books Ltd, 1998) ISBN: 9781857721423

First Steps: Number and Counting by D C Perkins and E J Perkins (Domino Books Ltd, 1998) ISBN: 9781857721331

Get Ready for Maths by N Morgan (Egmont Books Ltd, 2005) ISBN: 9781405215527

Let's Pretend Maths: Maths and Role Play by H Williams (BEAM, 2006) ISBN: 9781903142387

KS1 Year One Maths Workout Book by R Parsons

(Coordination Group Publications Ltd, 2001) ISBN: 9781841460826

Mirrors and Patterns (Maths Activity in Early Years) by D Wilson (Eigen Publications, 1984) ISBN: 9781850391272

Partnerships In Maths: Parents \& Schools Project by R Merttens and J Vass (Routledge Falmer, 1993) ISBN: 9780750701556

Starting Out: Foundation Stage mathematics by H Preston (BEAM, 2004) ISBN: 9781903142004 
It is crucial that prior to using any website with children that the practitioner visit the website in advance. This should be done to check that the information/material intended for use:

- supports the learning of the children

- is relevant to the work being explored

- is appropriate for the children.

BBC Number Time includes curriculum-relevant lesson plans, printable worksheets, online games and sing-along number songs.

www.bbc.co.uk/schools/numbertime

The Kent National Grid for Learning (KNGR) aims to support both teachers and pupils in the use of ICT across the curriculum by providing pages of resources, lesson ideas and links to 'safe' websites on the internet. The website also has many details regarding the use of the programmable toy featured earlier in this document.

www.kented.org.uk

Millennium Maths Project (MMP) was launched in 1999 and aims to support maths education and promote the development of mathematical skills and understanding, particularly through enrichment and extension activities beyond the school curriculum. www.mmp.maths.org

$\mathrm{NRICH}$ - Enriching Mathematics aims to raise the standards of achievement in school mathematics, to promote the mathematical development of children, and to support the special educational needs of very able children of all ages. They also promote and support the setting up of locally organised user groups and mathematics clubs through providing resources on the internet, as well as offering advice, inservice training and resources for teachers.

www.nrich.maths.org 


\section{Foundation Phase glossary}

\section{Active learning}

This term relates to children being active and involved in their learning. Children learn best through first-hand experiences. It is crucial that children have active experiences indoors and outdoors that build up the skills, knowledge and understanding that will support their future learning.

The purpose of play/active learning is that it motivates, stimulates and supports children in their development of skills, concepts, language acquisition/communication skills and concentration. It also provides opportunities for children to develop positive attitudes and to demonstrate awareness/use of recent learning, skills and competencies, and to consolidate learning.

\section{Assessment profile}

The assessment profile provides guidance on key child developmental stages and skills that children develop and acquire from approximately 18 months through to 84 months.

\section{Child initiated/centred}

The Foundation Phase curriculum should focus more on children's interests, development and learning rather than the curriculum and pre-determined outcomes. It is important to note that the planned curriculum has to have structure and clear learning objectives but enough flexibility to enable the children to follow their interests and their needs.

Careful observations of the planned curriculum and how children respond to it should provide evidence of whether the children are focused on their learning and not playing aimlessly. An understanding of child development is crucial to ensure that the children are extended in their learning.

\section{Cognitive development}

Cognitive development is the development of the mind. It focuses on children's thinking and understanding, imagination and creativity (including problem solving/reasoning/concentration and memory). 


\section{Communication/language development}

Language is made up of different forms and skills which include speaking and listening, reading, writing, thinking and observation. The tone of a voice is a powerful form of communicating meaning. Some children may use alternate systems to the voice such as signing.

Non-verbal communication also takes on different forms such as facial expressions (smiling), gestures/body movements (shoulders slouching and eye contact).

\section{Cooperative/group play}

Children start to play together, they share their play. Children become more sociable, take on roles in the play and take account of the roles of other children. They begin to be aware of the needs and wishes of their peers, so that gradually the play becomes more complex. Rules are sometime devised and some cooperative play will be revisited over several days.

\section{Cultural diversity}

The Foundation Phase supports the cultural identity of all children, celebrates different cultures and helps children recognise and gain positive awareness of their own and other cultures. Positive attitudes should be developed to enable children to become increasingly aware of and appreciative of the value of the diversity of cultures and languages that exist in Wales.

\section{Curriculum}

Seven Areas of Learning have been identified to describe an appropriate curriculum for 3 to 7 -year-olds that supports the development of children and their skills. They complement each other and work together to provide a curriculum that is holistic. Each Area of Learning includes the statutory education content (skills and range) that needs to be followed.

\section{Curriculum Cymreig}

The Foundation Phase contributes to the Curriculum Cymreig by developing children's understanding of the cultural identity unique to Wales across all Areas of Learning through an integrated approach. Children should appreciate the different languages, images, objects, sounds and tastes that are integral to Wales today, and gain a sense of belonging to Wales, and understand the Welsh heritage, literature and arts as well as the language. 


\section{Differentiation}

The curriculum should be flexible to match children's abilities, skills and developmental needs.

\section{Emotional well-being}

Emotional development focuses on the development of children's self-esteem, their feelings and their awareness of the feelings of others.

\section{Fine manipulative skills}

The development of children's fine manipulation/motor skills begins within the centre of their bodies and moves out. Through appropriate development, children will eventually be able to undertake fine and intricate movements. Fine manipulation skills include using finger movements and hand-eye coordination.

\section{Gross motor skills}

The development of gross motor skills starts with the young baby controlling head movements and then, moving down the body, controlling other parts of the body. Gross motor development includes using whole body movements, coordination and balance.

\section{Holistic curriculum}

The holistic curriculum is one where Areas of Learning are interlinked and learning and teaching support many aspects of the children's development rather than focusing on one specific stage or need. The curriculum is viewed and delivered as a whole.

\section{Imagination}

Imagination is having the skills and ability to form images, ideas and concepts that either exist but are not present, or that do not exist at all.

\section{Independence}

Independence refers to having the ability and skill to be less dependent on others. Skills of managing and coping should be progressively developed throughout the Foundation Phase.

\section{Learning styles}

There are different learning styles or preferred ways of interacting. The learning styles are: visual, auditory and kinaesthetic. When learning styles are taken into account learning can be enhanced. 
Some children learn best if they have a visual stimulus, others an auditory one or a kinaesthetic (practical) task. Research into brain development has shown that individual learning styles are affected by the environment, the type of learning activity and whether the child is working independently or in a group.

\section{Memory}

The memory is the part of the brain where information is collected, saved and later retrieved. Initially information has to be taken in and understood; it is then saved and recalled when needed. All of these processes are needed for learning to take place.

\section{Outcomes}

The Foundation Phase Outcomes incorporate baseline assessment scales and descriptions and the national curriculum level descriptions. They have been developed to support the end of phase statutory teacher assessment. There are six Outcomes per Area of Learning and for information purposes Outcomes $4-6$ broadly cross-reference to the current descriptions for Levels 1-3.

\section{Outdoor learning}

There is a strong emphasis on outdoor learning in the Foundation Phase. The outdoor learning environment should be an extension of the indoor learning environment. Structured experiential activities should be planned for throughout the day, and children should as far as possible (taking account of health and safety issues) be able to move freely between the indoors and outdoors.

\section{Parallel play}

Children may appear to be playing together, but closer observation reveals the children are actually playing alone and not interacting with each other. Children can be using the same equipment, or sitting or standing next to each other, but both are working independently of each other, with no interaction (either positive or negative) between them in their play.

\section{Partnership/associative play}

Children operating in the partnership/associative stage of play will begin to become aware of other children. They start to communicate with each other and are more aware of the play/games that other children are involved in. They begin to explain to each other what they are doing. Gradually one child will become involved in the other child's play. 


\section{Pedagogy}

Pedagogy refers to the relationships between learning and teaching. It embraces the concept of the practitioner as a facilitator of learning, responding to the needs of individuals, willing to learn alongside the children, using appropriate methods to manage the process of learning and continually reflecting on and improving practice.

\section{Personal development}

Personal development focuses on the children's awareness of themselves and the development of their self-help skills.

\section{Physical development}

Physical development focuses on increasing the skills and performance of the body. Physical and cognitive development are closely linked, especially during the early years. Physical development can be divided into gross motor skills and fine manipulative skills.

\section{Practitioners}

This generic term refers to the adults that work with children in the Foundation Phase. It includes teachers and classroom assistants in the maintained sector, and staff that work in the funded education settings in the non-maintained sector.

\section{Practitioner/adult guided}

Practitioners need to plan an appropriate curriculum that engages children in their learning. They need to encourage, motivate and develop attitudes. Practitioners need to be aware of when it is appropriate to intervene sensitively to extend children's learning, when to challenge their problem-solving and thinking skills, and when to allow the children to come to satisfactory conclusions on their own. Practitioners should support'scaffold' children's learning, observing, monitoring and assessing children's progress to ensure that they are moving on to the next stages of their development and that their skills are being extended.

\section{Problem solving}

Problem solving focuses on developing the ability to assess a problem/ situation then gathering information to find a solution/answer. As children's skills increase they will be able to draw on previous experiences when attempting new activities and solving problems. 


\section{Self-esteem}

This refers to the way children feel about themselves. Positive feelings indicate a high self-esteem, while negative feelings about themselves are an indication of low self-esteem.

\section{Skills framework}

The non-statutory Skills framework for 3 to 19-year-olds in Wales outlines progression in developing thinking, communication, number and information and communication technology (ICT).

\section{Social development}

Social development focuses on children's social interactions and relationships with their peers, practitioners and adults.

\section{Solitary play}

Children play contentedly alone. They are involved in their own play and will move from activity to activity regardless of any other children. Often in this stage of play children enjoy imitating everyday activities.

\section{Spectator play}

Children observe other children but do not join in. They like to watch other children playing. Often they can be observed standing/sitting on the fringes of where other children are playing. Although they can appear to be alone or lacking in confidence, they can often be concentrating while observing the play in order to develop an understanding of what to do.

\section{Statutory assessment}

Within the Foundation Phase there are two statutory assessments that have to be implemented: the baseline assessment and the end of phase statutory teacher assessment.

\section{Structured educational play}

Structured play experiences have specific planned outcomes to extend children's learning, skills and development. Structured play should be planned with flexibility so as to allow children opportunities to choose and extend an activity according to their interests and knowledge. 


\section{Acknowledgements}

The Curriculum and Assessment 3-14 Division of the Department for Children, Education, Lifelong Learning and Skills (DCELLS) would like to thank the many children, practitioners, parents, carers, settings, schools and other organisations who have helped in the production of this document, including:

All Wales Early Years Advisers

Cadle Primary School, Swansea

Caia Park Nursery School, Wrexham

Dolygaer Education Centre, Merthyr Tydfil

Holton Primary School, Barry

Kitchener Primary School, Cardiff

Llanilltud Faerdref Primary School, Pontypridd

Mount Airey Nursery and Infant School, Haverfordwest

Mudiad Ysgolion Meithrin

National Childminding Association

Old School Lane Playgroup, Llandudno

Pontllanffraith Primary School, Caerphilly

Troedyrhiw Infants School, Merthyr Tydfil

Ysgol Deiniol Marchwiel, Wrexham

Ysgol Rhiw Bechan, Newtown

Ysgol y Gogarth, Llandudno

Ysgol y Llys, Prestatyn. 